\title{
Zmiany warunków wodnych wskutek działalności górniczej w rejonie Galęzice-Bolechowice-Borków w Górach Świętokrzyskich
}

\author{
Jan Prażak ${ }^{1}$, Joanna Bruczyńska ${ }^{1}$, Dorota Kaczor-Kurzawa ${ }^{1}$, Tomasz Młyńczak ${ }^{1}$
}

\begin{abstract}
Changes of hydrologic conditions due to mining operations in the Galęzice-Bolechowice-Borków region, Holy Cross Mountains. Prz. Geol., 68: 233-236; doi: 10.7306/2020.10

A b s tr a c t. In the Gatęzice-Bolechowice-Borków region, located in the Holy Cross Mountains, several limestone and dolomite quarries are currently in operation. Deep drainage of these quarries caused the formation of a large regional depression cone that affected numerous groundwater intakes, including those supplying potable water for communes, and a large intake in the Dyminy quarter of Kielce. The range of the depression cone will increase in the future, both vertically and laterally, due to expanding extraction of industrial stones from continuously deepened mining levels. Prognoses of further changes of hydrologic conditions in the region and their impact on admissible volumes of groundwater resources available in particular intakes are calculated using the stationary mathematical model.
\end{abstract}

Keywords: Mine dewatering, depression cone, Holy Cross Mountains

Rejon Gałęzice-Bolechowice-Borków, przylegający do Kielc od południa, już od początku XX w. był miejscem intensywnej eksploatacji dewońskich wapieni i dolomitów, głównie dla potrzeb znajdujących się w nim cementowni, zakładów wapienniczych, zakładów kruszywa dla budownictwa i drogownictwa, cukrowni itp. Po wydobyciu kopaliny $\mathrm{z}$ poziomów niezawodnionych kopalnie zaczęły odwadniać wyrobiska i obecnie są one już eksploatowane poniżej pierwotnego zwierciadła wód podziemnych. Wapienie i dolomity dewonu środkowego i dolnej części dewonu górnego (franu) są jednocześnie ważnym zbiornikiem wód podziemnych. Zbiornik ten, ze względu na duże zasoby i dobrą jakość wody oraz znaczenie dla bieżącego i awaryjnego zaopatrzenia Kielc w wodę, posiada range głównego zbiornika wód podziemnych (GZWP) nr 418 (Kleczkowski, 1990; Górka i in., 2011). Trwające od wielu lat odwodnienie wyrobisk kopalń odkrywkowych spowodowało znaczne zmiany warunków wodnych i powstanie głębokiego, rejonowego leja depresji w środkowej i zachodniej części tego zbiornika. Lej kopalniany przekroczył nawet północno-zachodnią granicę rejonu Gałęzice-Bolechowice-Borków i objął fragment rejonu eksploatacji Kielce, który przylega od północy.

Warunki hydrogeologiczne ulegają ciągłym zmianom, w zależności od postępu w eksploatacji kopalin. Zasoby systemu wodonośnego są wzbogacane przez infiltrację wód powierzchniowych - w wyniku tego procesu niektóre rzeki zostały już całkowicie osuszone. Odprowadzane do rzek wody kopalniane o dobrej jakości wzbogacają objętość przepływu wód rzecznych i poprawiają ich jakość.

Rozwój rejonowego leja depresji jest na bieżąco śledzony w punktach obserwacyjnych monitoringów lokalnych kopalń i dużych ujęć wód podziemnych. Wszelkie prognozy zawodnienia wyrobisk na coraz niższych poziomach eksploatacyjnych, wzrostu poboru wody z ujęć i zasięgu oddziaływania odwodnienia są obliczane głównie $\mathrm{z}$ zastosowaniem stacjonarnego, hydrogeologicznego modelu matematycznego lub innych modeli pojedynczych obiektów hydrologicznych. Według modelu stacjonarnego są obliczane także prognozy wpływu odwodnień górniczych na zasoby dyspozycyjne GZWP nr 418 i eksploatacyjne ujęć wód podziemnych.

\section{OBSZAR BADAŃ}

Rejon badań leży w południowej Polsce na Wyżynie Małopolskiej, w zlewni II rzędu Nidy (III rzędu Białej Nidy i Czarnej Nidy, IV rzędu Łososiny, Hutki, Bobrzy i Lubrzanki). Obejmuje on synklinę gałęzicko-bolechowicko-borkowską, wykształconą w utworach dewońskich Gór Świętokrzyskich, wraz z otaczającymi ją od zachodu utworami permu i triasu obrzeżenia mezozoicznego. Na tle podziału hydrogeologicznego jest to region X-środkowomałopolski (Paczyński, 1993) lub subregion środkowej Wisły - wyżynny - część centralna (Prażak, 2007a).

\section{EKSPLOATACJA SKAL WEGLANOWYCH I ODWODNIENIA GÓRNICZE}

Dewońskie wapienie już w latach przedwojennych były wydobywane na potrzeby miejscowego przemysłu wapienniczego. Po wojnie nastapił intensywny wzrost ich wydobycia, związany $\mathrm{z}$ wybudowaniem zakładów wapienniczych, cementowo-wapienniczych i cukrowni oraz potrzebą zaspokojenia innych gałęzi gospodarki narodowej, m.in. przemysłu budowlanego i drogownictwa. Pierwsze odwadniane wyrobisko w Zgórsku zostało zalane wodą w latach 80. XX w. Jednocześnie od początku lat 70. XX w. rozpoczęto odwadnianie kolejnych wyrobisk. Wielkość odwodnienia wynosi obecnie (2018 r.): Ostrówka $\left(1435 \mathrm{~m}^{3} / \mathrm{h}\right)$, Jaźwica $\left(102 \mathrm{~m}^{3} / \mathrm{h}\right)$, Trzuskawica $\left(502 \mathrm{~m}^{3} / \mathrm{h}\right)$, Kowala $\left(69 \mathrm{~m}^{3} / \mathrm{h}\right)$ i Radkowice $\left(1093 \mathrm{~m}^{3} / \mathrm{h}\right)$. Wody kopalniane są pompowane $\mathrm{z}$ rząpi $\mathrm{w}$ dnie wyrobisk i po przejściu przez osadniki odprowadzane do rzek.

W 2019 r. zakończono eksploatację kopaliny ze złoża Radkowice i trwa jego rekultywacja wodna (zatapianie dopływającymi wodami podziemnymi. W zamian kopalnia zamierza w najbliższym czasie wydobywać kopalinę

\footnotetext{
${ }^{1}$ Państwowy Instytut Geologiczny - Państwowy Instytut Badawczy, Oddział Świętokrzyski, ul. Zgoda 21, 25-953 Kielce; jan.prazak@pgi.gov.pl
} 
poniżej zwierciadła wody z sąsiedniego złoża Kowala Mała (ryc. 1).

Środkowo- i górnodewoński zbiornik wodonośny oraz obszary jego zasilania zaopatrują w wodę południową część Kielc i lokalne wodociagi gminne. Pełnią także rolę awaryjnego źródła wody dla Kielc w sytuacjach nadzwyczajnych. Najważniejszymi ujęciami wody są: 1) Lesica $\left(39,6 \mathrm{~m}^{3} / \mathrm{h}\right)$ - dla wodociągu gminy Piekoszów, 2) ujęcie Wojewódzkiego Szpitala w Czerwonej Górze $\left(39,0 \mathrm{~m}^{3} / \mathrm{h}\right)$, 3) Bolechowice $\left(136,2 \mathrm{~m}^{3} / \mathrm{h}\right)$ - dla wodociagu gminy Sitkówka-Nowiny, 4) Kielce-Dyminy $\left(450,0 \mathrm{~m}^{3} / \mathrm{h}\right)$ - dla Kielc i 5) Niwy Daleszyckie $\left(13,1 \mathrm{~m}^{3} / \mathrm{h}\right)$ - dla wodociagu gminy Daleszyce. Poza ostatnim z wymienionych wszystkie pozostałe ujęcia znajdują się w obszarze oddziaływania odwodnień górniczych - w rejonowym leju depresji. W 2018 r. łączny pobór wody ze wszystkich czynnych ujęć w rejonie wynosił $291 \mathrm{~m}^{3} / \mathrm{h}$ (Młyńczak i in., 2019).

Leje depresji kopalń i ujęć wód podziemnych uległy połączeniu, w wyniku czego w środkowej i zachodniej części rejonu powstał jeden duży rejonowy lej depresji. Będzie się on nadal utrzymywał i rozwijał w zależności od postępu w eksploatacji kopalin. Kopalnie są zainteresowane prognostycznymi obliczeniami zawodnienia coraz niższych poziomów eksploatacyjnych, natomiast lokalna społeczność szkodami spowodowanymi działalnością górniczą, w tym oddziaływaniem odwodnień na zasoby wód podziemnych.

Bilans wodny obliczono na podstawie obecnego stanu warunków hydrogeologicznych według modelu matematycznego (tab. 1) sporządzonego w 2005 r. przez hydrogeologów z Oddziału Świętokrzyskiego Państwowego Instytutu Geologicznego - Państwowego Instytutu Badawczego (PIG-PIB). Model ten do dziś pełni w pewnym sensie rolę stacjonarnego modelu opisywanego rejonu eksploatacji wód podziemnych (Prażak i in., 2005; Młyńczak i in., 2019). Zasięg rejonowego leja depresji, obliczony według tego modelu, ukazuje ryc. 1 .

Wody kopalniane odprowadzane do rzek Hutka i Bobrza są dobrej jakości i spełniają wymogi wody przeznaczonej do spożycia przez ludzi. Są to wody wodorowęglanowo-wapniowe i wodorowęglanowo-wapniowo-magnezowe o mineralizacji średnio ok. $335 \mathrm{mg} / 1$ (Prażak, 2007b). Wzbogacają one objętość przepływu wód rzecznych, co ma

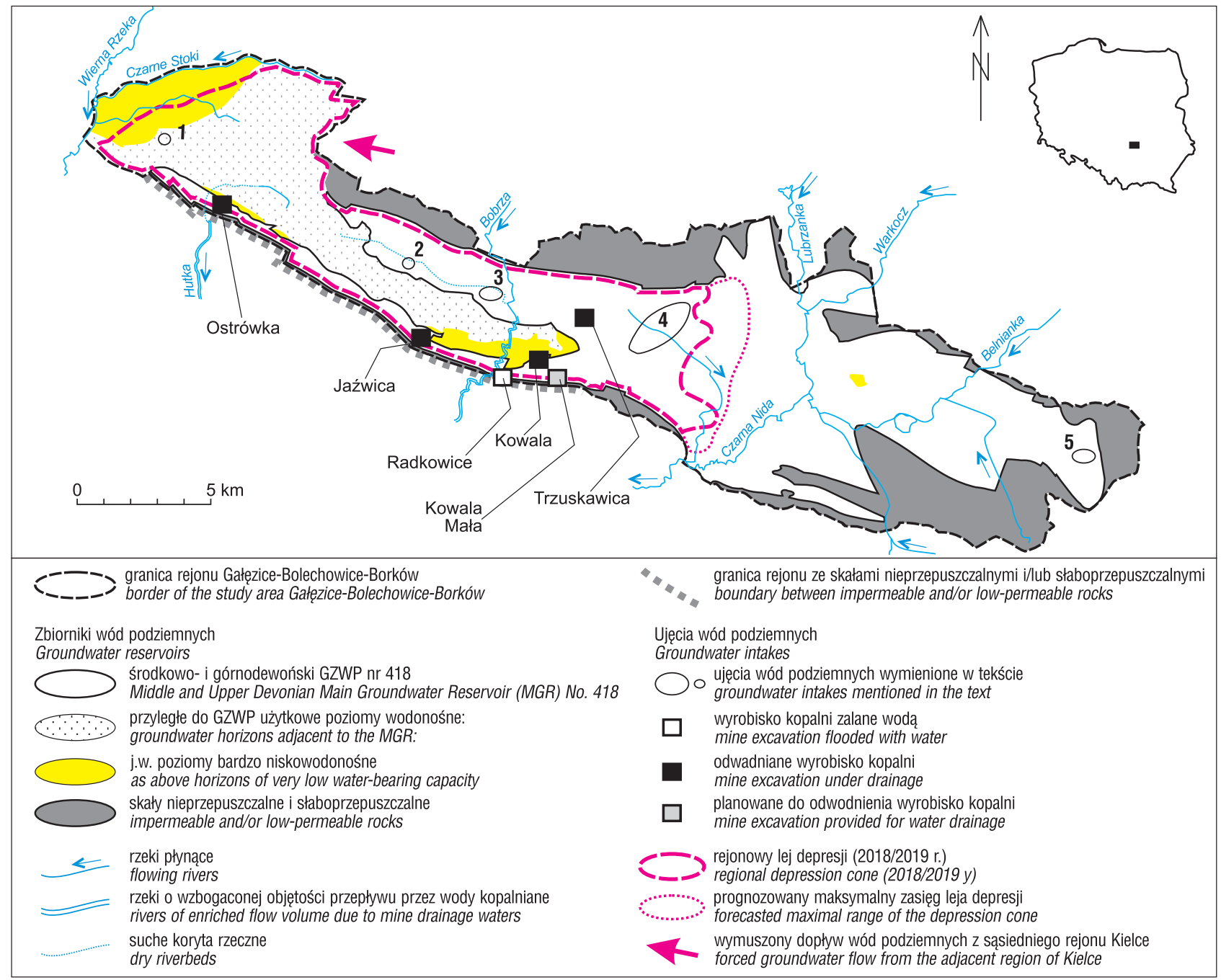

Ryc. 1. Zasięg zmian warunków wodnych w rejonie eksploatacji kopalin węglanowych w rejonie Gałęzice-Bolechowice-Borków. Ujęcia wód podziemnych: 1 - Lesica; 2 - ujęcie Wojewódzkiego Szpitala w Czerwonej Górze; 3 - Bolechowice; 4 - Kielce-Dyminy i 5 - Niwy Daleszyckie

Fig. 1. The range of groundwater regime changes within the carbonate raw material exploitation region of Gałęzice-Bolechowice-Borków. Groundwater intakes: 1 - Lesica; 2 - ujęcie Wojewódzkiego Szpitala w Czerwonej Górze; 3 - Bolechowice; 4 - Kielce-Dyminy and $\mathbf{5}$ - Niwy Daleszyckie 
istotne znaczenie dla stanów niżówkowych rzek (ryc. 1). Wpływają także na poprawę jakości wód rzecznych.

\section{PROGNOSTYCZNE OBLICZENIA ZMIAN WARUNKÓW WODNYCH WEDLUG MODELU MATEMATYCZNEGO}

Spośród wielu prognoz zawodnienia wyrobisk i zasięgu leja depresji, obliczonych według modelu matematycznego, w niniejszym artykule przedstawiono wyniki obliczeń wariantu zakładającego:

$\square$ jednoczesne odwodnienie wszystkich obecnie odwadnianych kopalń na najniższych poziomach eksploatacyjnych;

$\square$ pobór wody ze wszystkich obecnie czynnych ujęć w ilości aktualnych pozwoleń wodnoprawnych.

Jest to wariant graniczny maksymalnych zmian warunków hydrogeologicznych, tzw. wariant widmo. Kopalnie będą bowiem kończyć eksploatację w różnym czasie, a ich wyrobiska zostaną zalane dopływającą wodą podziemną, co z kolei będzie zmniejszać zasięg oddziaływania odwodnienia. Obliczony dla tego wariantu zakres zmian zasięgu leja depresji będzie już niewielki (ryc. 1), z tym, że zwiększy się wyraźnie dopływ wody z rejonu eksploatacji Kielce (Różkowski i in., 2017). Zwiększy się też infiltracja wód rzecz- nych i obniży się zwierciadło wody w studniach wierconych ujęć wody. Bilans wodny tego wariantu ukazano w tabeli 1, a obliczone docelowe dopływy wód podziemnych do poszczególnych wyrobisk będą wynosić: Ostrówka $1279 \mathrm{~m}^{3} / \mathrm{h}$ (ryc. 2), Jaźwica $503 \mathrm{~m}^{3} / \mathrm{h}$, Trzuskawica $699 \mathrm{~m}^{3} / \mathrm{h}$ (ryc. 3), Kowala $199 \mathrm{~m}^{3} / \mathrm{h}$ i Kowala Mała $111 \mathrm{~m}^{3} / \mathrm{h}$ - łącznie $2791 \mathrm{~m}^{3} / \mathrm{h}$ (Młyńczak i in., 2019).

\section{WPLYW ODWODNIEŃ GÓRNICZYCH NA ZASOBY WÓD PODZIEMNYCH}

Odwodnienia górnicze i wywołane nimi zmiany warunków wodnych powodują, że w systemie wodonośnym następuje przyspieszenie krążenia wód podziemnych. Nie ulegają zmniejszeniu pochodzące $\mathrm{z}$ infiltracji efektywnej zasoby odnawialne. System ten jest dodatkowo wzbogacony przez infiltrujące wody powierzchniowe. Tym samym nie ulegają zmniejszeniu jego zasoby dyspozycyjne, oszacowane na $3521 \mathrm{~m}^{3} / \mathrm{h}$ (Rodzoch i in., 2012).

Nieco inaczej wygląda natomiast sytuacja zasobów ujęć eksploatacyjnych. Zwierciadło wody w studniach znajdujących się w leju depresji ulega obniżeniu. Skutkuje to większymi depresjami eksploatacyjnymi. Jeśli studnia jest odpowiednio głęboka i ma konstrukcję pozwalającą na opuszczenie pompy na większą głębokość, to jej zasoby

Tab. 1. Bilans wodny rejonu Gałęzice-Bolechowice-Borków dla stanów: pseudonaturalnego, obecnego (2018 r.) i prognozy docelowego odwodnienia wyrobisk górniczych

Table 1. Groundwater balances in the region of Gałęzice-Bolechowice-Borków for various conditions: pseudonatural state, current state (2018 y.) and prognosis of the target state of the mine excavation drainage

\begin{tabular}{|c|c|c|c|c|c|c|}
\hline \multirow{2}{*}{$\begin{array}{l}\text { Element bilansu } \\
\text { Components } \\
\text { of the balance }\end{array}$} & $\begin{array}{c}\text { Stan } \\
\text { pseudonaturalny } \\
\text { Pseudonatural } \\
\text { state } \\
\end{array}$ & $\begin{array}{l}\text { Stan obecny } \\
(2018 \text { r.) } \\
\text { Current state } \\
\quad(2018) \\
\end{array}$ & $\begin{array}{l}\text { Prognoza stanu } \\
\text { docelowego } \\
\text { Prognosis } \\
\text { of target state }\end{array}$ & $\begin{array}{c}\text { Stan } \\
\text { pseudonaturalny } \\
\text { Pseudonatural } \\
\text { state } \\
\end{array}$ & $\begin{array}{l}\text { Stan obecny } \\
(2018 \text { r.) } \\
\text { Current state } \\
\quad(2018) \\
\end{array}$ & $\begin{array}{l}\text { Prognoza stanu } \\
\text { docelowego } \\
\text { Prognosis } \\
\text { of target state }\end{array}$ \\
\hline & \multicolumn{3}{|c|}{$\begin{array}{c}\text { Zasilanie }\left[\mathrm{m}^{3} / \mathrm{h}\right] \\
\text { Recharge rate }\left[\mathrm{m}^{3} / \mathrm{h}\right]\end{array}$} & \multicolumn{3}{|c|}{$\begin{array}{c}\text { Drenaż }\left[\mathrm{m}^{3} / \mathrm{h}\right] \\
\text { Drainage rate }\left[\mathrm{m}^{3} / \mathrm{h}\right]\end{array}$} \\
\hline $\begin{array}{l}\text { Infiltracja efektywna } \\
\text { opadów atmosferycznych } \\
\text { Effective infiltration from } \\
\text { atmospheric precipitation }\end{array}$ & 3752 & 4128 & 4077 & & & \\
\hline $\begin{array}{l}\text { Infiltracja wód rzecznych } \\
\text { Infiltration from river } \\
\text { waters }\end{array}$ & 165 & 1414 & 1427 & & & \\
\hline $\begin{array}{l}\text { Odpływ do rzek } \\
\text { Outflow to river waters }\end{array}$ & & & & 3828 & 1927 & 1742 \\
\hline $\begin{array}{l}\text { Zasilanie przez infiltrację } \\
\text { wody z zalanego wodą } \\
\text { wyrobiska Radkowice } \\
\text { (zbiornik przeplywowy) } \\
\text { Recharge by infiltration } \\
\text { of water from a flooded } \\
\text { Radkowice mine } \\
\text { excavation (flow } \\
\text { reservoir) }\end{array}$ & & & 46 & & & \\
\hline $\begin{array}{l}\text { Odwodnienie wyrobisk } \\
\text { górniczych } \\
\text { Drainage of mining } \\
\text { excavations }\end{array}$ & & & & & 3296 & 2791 \\
\hline $\begin{array}{l}\text { Pobór wody z ujęć } \\
\text { Water extraction from } \\
\text { intakes }\end{array}$ & & & & & 291 & 932 \\
\hline $\begin{array}{l}\text { Ewapotranspiracja } \\
\text { Evapotranspiration }\end{array}$ & & & & 89 & 88 & 85 \\
\hline $\begin{array}{l}\text { Razem } \\
\text { Total }\end{array}$ & 3917 & 5542 & 5550 & 3917 & 5542 & 5550 \\
\hline
\end{tabular}




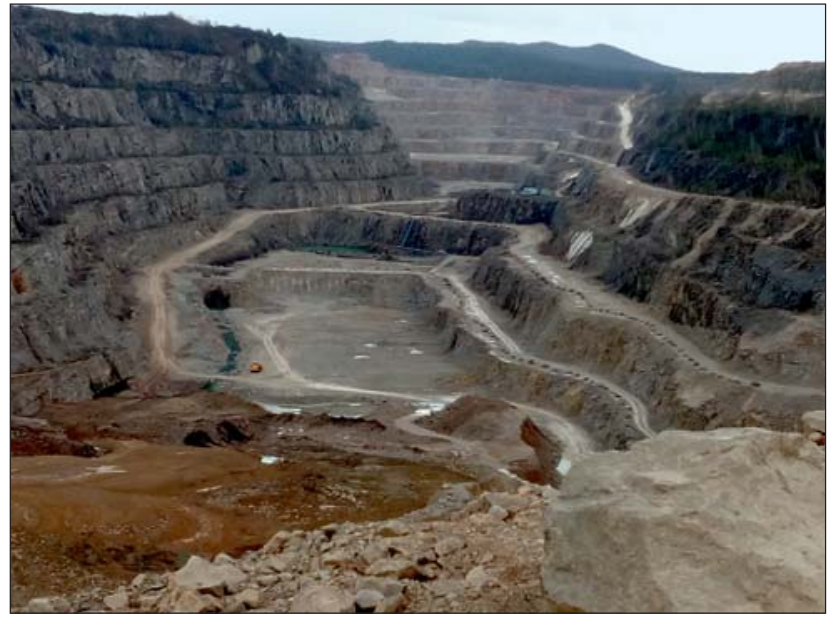

Ryc. 2. Wyrobisko Ostrówka kopalni w Miedziance. Ryc. 2 i 3 fot. T. Młyńczak

Fig. 2. Excavation of the Ostrówka mine in Miedzianka. Fig. 2 and 3 - photo by T. Młyńczak

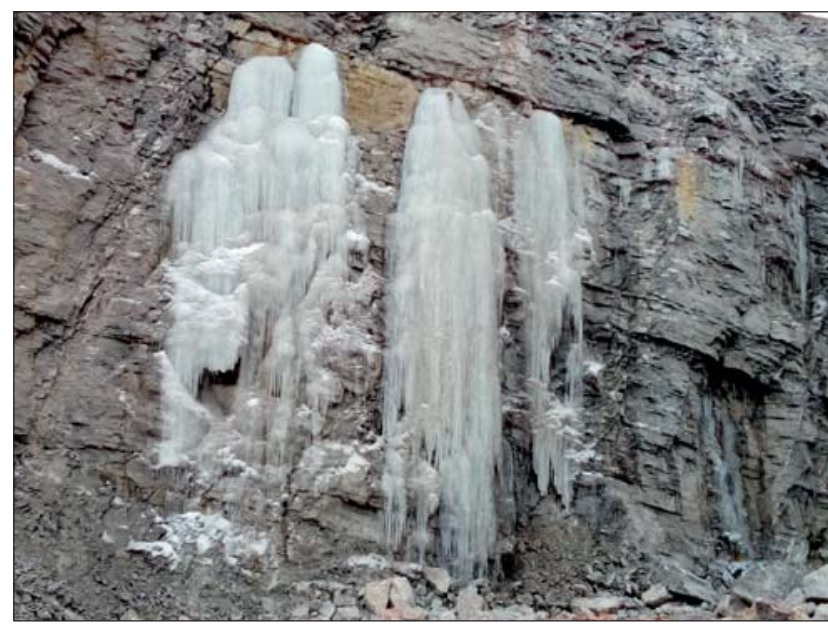

Ryc. 3. Galerie lodowe z wypływów wody ze ściany wyrobiska kopalni Trzuskawica

Fig. 3. Ice galleries originated due to water outflows from excavation wall of the Trzuskawica mine

eksploatacyjne mogą pozostać bez zmian, a wymagana jest tylko korekta samej depresji eksploatacyjnej. Jeśli jest to niemożliwe ze względu na głębokość i konstrukcję studni, to konieczne jest jej pogłębienie lub dowiercenie nowych studni na terenie ujęcia.

W rejonie odwadnianych wyrobisk jest prowadzony lokalny monitoring stanu zwierciadła wód podziemnych. Pomiary zwierciadła wody są wykonywane na ogół co jeden miesiąc. Sieci monitoringu zorganizowanego wokół poszczególnych kopalń liczą od kilku do kilkunastu punktów. Ich liczba nie zawsze jest wystarczająca do zaspokojenia potrzeb bieżącej kontroli stanu pola hydrodynamicznego wód podziemnych w skali rejonu. Nie sprzyja jej także brak ośrodka, w którym by były na bieżąco analizowane wyniki wszystkich monitoringów w rejonie badań.

\section{PODSUMOWANIE}

Warunki hydrogeologiczne rejonu Gałęzice-Bolechowice-Borków od wielu lat pozostają pod wpływem zmian powodowanych działalnością górniczą. Wapienie i dolomity są wydobywane z głębokich, odwadnianych poziomów eksploatacyjnych kopalń zlokalizowanych w środkowej i zachodniej części rejonu. Obniżenie zwierciadła wód podziemnych w rejonowym leju depresji wpływa bezpośrednio na parametry eksploatacyjne ujęć wody (depresja i wydajność), co stwarza często potrzebę głębszego zapuszczenia pompy, pogłębienia otworu studziennego lub wykonania dodatkowych studni. Wody kopalniane odprowadzane obecnie do rzek są dobrej jakości i przy zmianie sposobu odwodnienia z rząia na bariery studni wierconych mogą być wykorzystane do celów komunalnych, przemysłu i rolnictwa (Prażak, 2012, 2019).

\section{LITERATURA}

GÓRKA J., BIEDROŃSKI G., KAŁUS D., SZKLARCZYK T. 2011 Dokumentacja hydrogeologiczna określajaca warunki hydrogeologiczne w związku z ustanowieniem obszarów ochronnych Głównego Zbiornika Wód Podziemnych nr 418 Gałęzice-Bolechowice-Borków. Arch. Krakowskiego Przeds. Geol. ProGeo Sp. z o.o., Kraków.

KLECZKOWSKI A.S. (red.) 1990 - Mapa obszarów głównych zbiorników wód podziemnych (GZWP) w Polsce wymagających szczególnej ochrony 1:500 000. AGH, Kraków.

MŁYŃCZAK T., BRUCZYŃSKA J., PRAŻAK J., KOS. M., BIAŁECKA K., LIPIEC I., MILIANOWICZ A., STAŃCZYK E. $2019-$ Dokumentacja hydrogeologiczna określajaca warunki hydrogeologiczne w związku z odwodnieniem złoża wapieni Trzuskawica do rzędnej +180 m n.p.m. Arch. Państw. Inst. Geol., Oddział Świętokrzyski, Kielce.

PACZYŃSKI B. (red.) 1993 - Atlas hydrogeologiczny Polski 1:500 000, cz. I: Systemy zwykłych wód podziemnych. Państw. Inst. Geol.

PRAŻAK J. 2007a - Subregion środkowej Wisły wyżynny czesść centralna. [W:] Paczyński B., Sadurski A. (red.), Hydrogeologia regionalna Polski. Państw. Inst. Geol.: 174-187.

PRAŻAK J. 2007b - Tło hydrochemiczne jako standard jakości wód podziemnych zbiornika szczelinowo-krasowego Gałęzice-Bolechowice-Borków w Górach Świętokrzyskich. Współczesne problemy hydrogeologii XIII, Kraków-Krynica. AGH: 593-603.

PRAŻAK. J. 2012 - Pozycja hydrodynamiczna i znaczenie gospodarcze dewońskich zbiorników wód podziemnych w Górach Świętokrzyskich. Pr. Państw. Inst. Geol., 198.

PRAŻAK J. 2019 - Hydrogeologia zlewni Nidy oraz problemy zagospodarowania i ochrony wód podziemnych. [W:] Informator PSH. Państw. Inst. Geol.

PRAŻAK J., JANECKA-SYRCZ K., KOS M., KOWALCZEWSKA G., MACHOWSKA K., MŁYŃCZAK T., WRÓBLEWSKA E. 2005 Wskazanie możliwości pozyskania dla miasta Kielce wód kopalnianych z obszaru Gałęzice-Bolechowice-Borków wraz z określeniem wpływu odwodnień górniczych na zasoby komunalnych ujęć wód podziemnych Kielc - na podstawie badań modelowych. Arch. Państw. Inst. Geol., Oddział Świętokrzyski, Kielce.

RODZOCH A., MUTER K., WIEWIÓRA A., MANUSZAK M., JELENIEWICZ G., URSZULAK M. 2012 - Dokumentacja hydrogeologiczna ustalająca zasoby dyspozycyjne wód podziemnych zlewni Nidy bez rejonu Kielc. Arch. HYDROEKO Biuro Poszukiwań i Ochrony Wód Andrzej Rodzoch, Warszawa.

RÓŻKOWSKI K., ZDECHLIK R., KAZANOWSKA-OPALA K. 2017 Dodatek nr 3 dokumentacji hydrogeologicznej ustalającej zasoby eksploatacyjne ujęcia komunalnego w Kielcach-Białogonie. Arch. Fundacji Nauka i Tradycje Górnicze, Kraków. 